\title{
Endoscopic excision of meningocele and meningoencephalocele - report of two cases
}

\author{
Sheikh Hasanur Rahman ${ }^{1}$, Kamrul Hassan Tarafder ${ }^{2}$, Mohammad Asaduzzaman Rasel'. \\ ${ }^{1}$ Associate professor, Department of Otolaryngology ${ }^{2}$ Professor, Department of Otolaryngology, BSMMU ${ }^{3}$ Consultant, ENT and Head-Neck Cancer Hospital and institute, Dhaka.
}

\begin{abstract}
:
Meningocele and meningoencephalocele are rare entities produced by herniation of cranial contents at the defective areas of the skull base, which may be congenital, spontaneous or traumatic. The condition may present as CSF rhinorrhoea, nasal obstruction or even with meningitis. Management of these basal encephaloceles with endoscopic surgery provides a direct view of the skull base and cause less morbidity compared with transcranial approach. Two cases have been reported here, first, a meningocele presented as a case of recurrent CSF rhinorrhoea and the second one, a meningoencephalocele presented as recurrent meningitis, treated using an endoscopic procedure and reviews the literature regarding their management.
\end{abstract}

Key Word: Meningocele; Meningoencephalocele; Endoscopic excision

[BSMMU J 2014; 7 (1) : 53-57]

\section{Introduction:}

Basal encephalocoeles are rare entities produced by herniations of cranial contents at the defective areas of the base of the skull1. They may be congenital, spontaneous or traumatic (iatrogenic or from head injury) $)^{2}$. They may present with cerebrospinal fluid (CSF) leak, meningitis, brain abscess, nasal obstruction, facial deformity (in congenital cases) $)^{2-7}$. In some it may go undetected until it is noted incidentally on imaging studies?

Endoscopic surgery provides a direct view of the skull base and is associated lower morbidity rates compared with the transcranial approach in the treatment of CSF leakage ${ }^{8,9}$. As the instruments progressively improve, various surgeons have recommended endoscopic surgery for the treatment of more challenging entities, such as basal encephalocoeles ${ }^{10-14}$. It can also be perfomed in very young children ${ }^{15}$.

In recent years this method has become popular among ENT surgeons and neurosurgeons. In this report, two

Address for Correspondence: Dr. Sheikn Hasanur Rahman Associate Professor Dep. of Otolaryagology, BSMMU, Mobile: 01711540139 cases, first one meningocele with recurrent CSF rhinorrhoea and second one meningoencephalocoele with recurrent meningitis, are presented and reviewed possible treatment options.

\section{Case Reports:}

Case 1:

1. A 45-year-old male was admitted in the Department of Otolaryngology, Bangabandhu Sheikh Mujib Medical University in April 2007 with the history of clear watery discharge from right nasal cavity and right-sided nasal obstruction for 3 years. He had no history of fever, convulsion, loss of consciousness, or head injury. He was previously hospitalized three times, diagnosed as a case of recurrent CSF rhinorrhoea and each time treated conservatively. Nasoendoscopic examination showed a large grayish, glistening, smooth, pulsatile mass in the right nasal cavity. A coronal computed tomography scan revealed a right-sided cystic nasal mass, deviating the septum to the opposite side, and there was bony dehiscence in the floor of anterior cranial fossa in right paramedian area. Findings of biochemical examination of nasal discharge were consistent with CSF. 
With a diagnosis of meningocele, he underwent a endonasal endoscopic procedure. Under general anesthesia, using nasoendoscope, the meningocele sac was identified (Fig-1). The sac was first shrinked using low voltage bipolar cautery and then redundant part was dissected and resected meticulously. During the excision, cerebrospinal fluid (CSF) leak was observed. A bone defect of about 8 $\mathrm{mm}$ in size was identified at the cribriform plate. The defect was repaired in layers using fascia lata, and a piece of septal cartiledge by underlay technique (Fig-2). Nasal cavity was packed first by a large piece of gelfoam and then by BIPP pack. Lumber drain was not used.

The patient was discharged from hospital on $10^{\text {th }}$ postoperative day after removing the BIPP pack, with no sign of CSF leak, infection. Follow up was done regularly by nasoendoscope and treated accordingly. There was no evidence of CSF leak or herniation through the roof of the nose till the last follow up in November 2010.

\section{Case 2:}

A 7-year-old boy admitted in the hospital on January 2008 with history of recurrent meningitis for last one year. $\mathrm{He}$ also complaint of right sided nasal obstruction for last 6 month. He was hospitalized several times with meningitis and was treated conservatively. Nasoendoscopic examination revealed a smooth globular grayish white pulsatile mass in the right nasal cavity (Fig-3). On aspiration clear watery fluid came out; findings of laboratory tests were consistent with CSF. Computed tomography scan showed a soft tissue mass with heterogenous enhancement in the anterior superior part of right nasal cavity. Bony dehiscence was seen in right half of cribriform plate pushing the crista galli to left side.

Preoperatively it was diagnosed as a case of meningoencephalocele, and underwent endoscopic excision. The sac was dissected and excised by using low voltage bipolar diathermy; small portion of the brain matter was also excised. Bony dehiscence was repaired by underlay technique using fascia lata and a piece of septal cartiledge in layers. Nasal cavity was packed by Gelfoam and BIPP pack, which was removed after 8 days. Post operative recovery was uneventful. We didn't use lumber drain.

The patient was followed up periodically with no recurrence of nasal mass, meningitis or CSF leak till the last follow up in Nov. 2010.

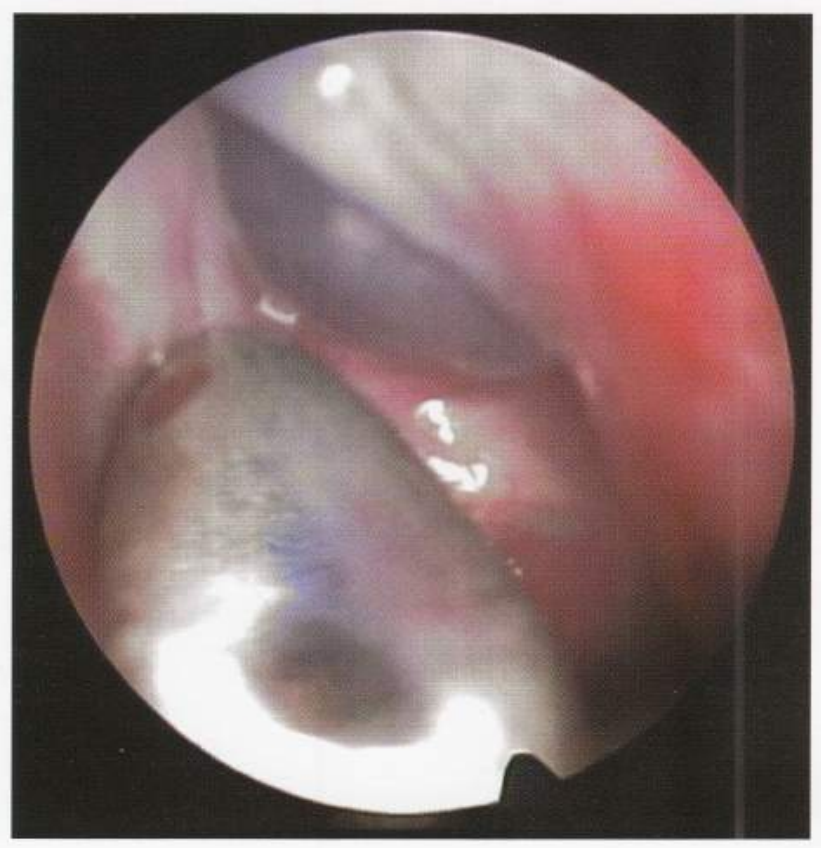

Fig 1 : A meningocoele between nasal septum and middle turbinate

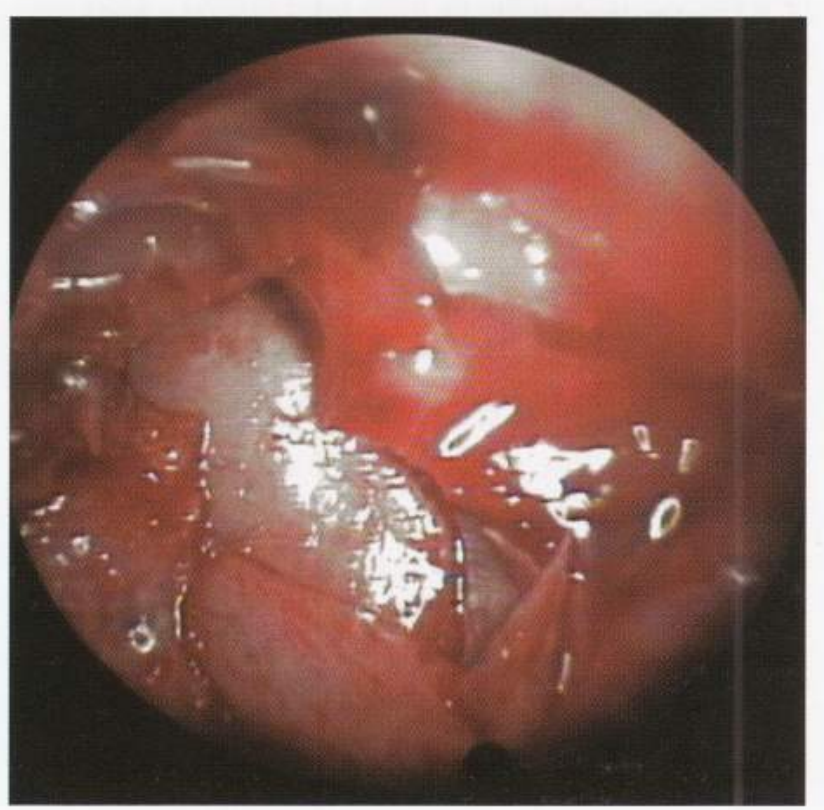

Fig 2: Large skull base defect after removal of meningoencephalocoele; underlay fascia lata and nasal septal cartilage underlay grafts are in situ. 


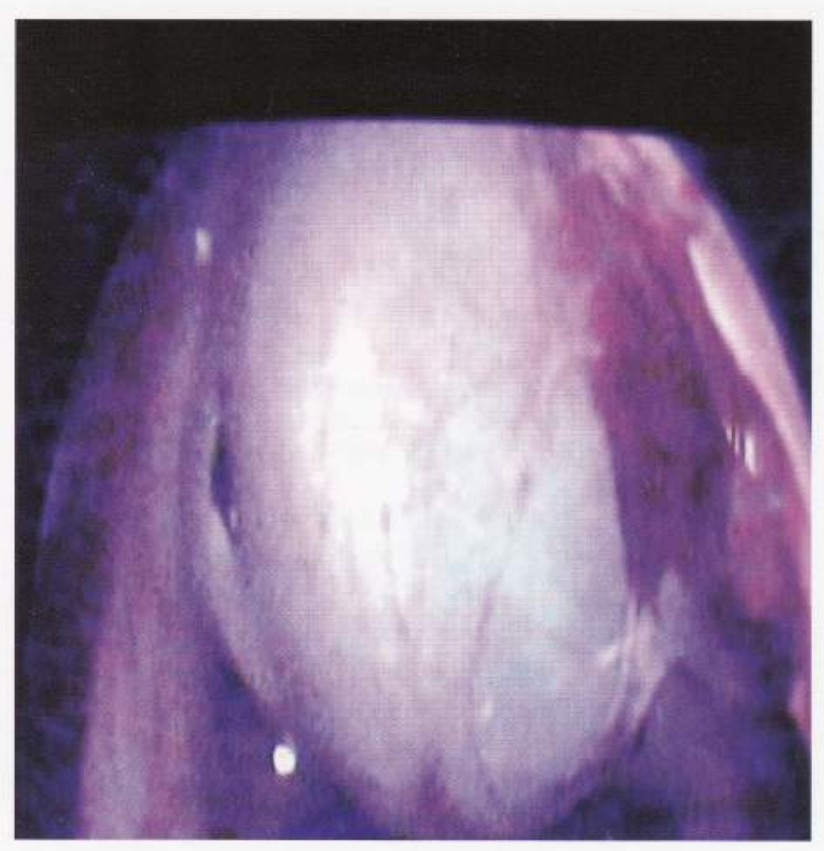

Fig 3: A meningoencephalocoele protruding through cribriform plate Case

\section{Discussion:}

The management of meningocele or meningoencephalocele has changed dramatically with nasal endoscopic techniques. Historically, these lesions were approached with a bicoronal incision and frontal craniotomy. Often it was necessary a pericranial flap in order to reconstruct the skull base defects ${ }^{3,16}$.

Unfortunately some disadvantages of transcranial approaches were anosmia, intracranial hemorrhage or edema, epilepsy, frontal lobe retraction, and memory or concentration deficits $^{16}$. It also has a long hospital stay, less patient's comfort and a visible $\operatorname{scar}^{17-24}$. Furthermore, failure rates for CSF rhinorrhea can be as high as $30 \%$. Many of these complications were avoided by using nasal endoscopic techniques. The endoscopic excision of intranasal encephaloceles, meningoceles, meningoencephaloceles, and repair of cerebrospinal fluid (CSF) leaks in adults, mostly traumatic or iatrogenic, has become the standard of care ${ }^{5-8}$.

Meningo-encephaloceles and associated CSF leaks remain a surgical challenge. Many of these lesions can be diagnosed by direct visualization with a nasal endoscope. High-resolution CT with contrast help to corroborate the site of origin to ascertain the extent of the skull base defect and to rule out other sinonasal and intracranial pathology or the presence of vessels within the herniated tissue ${ }^{3}$.

MRI can complement the anatomical information provided by CT in terms of the size and location of the stalk of the lesion and the presence of vessels within the sac. MR cisternography does not require the intrathecal administration of a contrast agent and may become the imaging modality of choice for the evaluation of CSF fistulae. MR cisternography is noninvasive and has a reported sensitivity, specificity, and accuracy of $87 \%$, $57 \%$, and $96 \%$, respectively, when combined with coronal $\mathrm{CT}^{25}$. Traditionally, CSF leaks have been managed via a craniotomy. Initially, the extracranial repair of CSF leaks involved an external ethmoidectomy approach and the use of a mucosal pedicled flap to close the CSF fistula. Subsequently, free tissue grafts followed by transnasal techniques were advocated. Microscopic transnasal techniques for the repair of CSF leaks predate endoscopic technology; however, transnasal repairs became more popular with the advent of endoscopic sinus surgery. Since the first description of endoscopic closure of CSF leaks by Wigand in 1981, multiple reports have described a number of different grafting techniques ${ }^{10}$.

The choice of materials and techniques used during the endoscopic repair of CSF fistulae depends mostly on the experience and preference of the operating surgeon. In experienced hands, most techniques yield similar results $^{27}$. The critical for all grafting techniques is that the mucosa surrounding the defect should be removed to allow the graft to adhere firmly to the skull base. Herniated dura, brain, or both can be managed with resection or reduction into the intracranial cavity. Most authors agree with transection or resection of the pedicle because encephaloceles seldom contain functional brain tissue, and the intranasal portion is considered to be contaminated ${ }^{28}$.

The inlay/underlay, onlay, and obliteration techniques have no significant differences in outcome. Typically, an underlay technique with bone or cartilage, fat, and/or muscle plugs is used for large, bony defects associated with a meningoencephalocele. In addition, various materi- 
als can be used to fixate the grafts and/or flaps in place, such as Surgicel, Gelfoam and Gelfilm, and fibrin glue $^{3}$. Burns et al. used the endoscope to manage 42 patients with fistulae ${ }^{29}$. They supported the use of a free mucosal graft with fibrin glue for defects of the cribriform plate and roof of the ethmoid. In Zweig et al series, fibrin glue, although subjectively helpful, did not appear to be critical to obtaining an adequate closure ${ }^{3}$. Conversely, it does not guarantee success as illustrated by a meta-analysis of the literature by Hegazy et $\mathrm{al}^{30}$.

The aspects of perioperative management like the use of prophylactic antibiotics, the use of nasal packing, and diversion of the CSF, either with a lumbar drain or a VP shunt are controversial and argued in different literatures. We used antibiotic soaked Gelfoam as fixator and Bismath Iodine paste pack and kept it for 8-10 days. Some authors prefer removing nasal pack early. We didn't use lumber drain in our cases. In some studies, the authors used lumber drain after endoscopic surgery while in others, they didn't use it ${ }^{2,31}$. In a study it has been found that there is no significant difference between using or not using lumber drain; however those with hydrocephalus requires a permanent CSF diversion (eg. VP shunt $)^{20}$.

Hydrocephalus and meningitis are the common causes of failure for transnasal endoscopic repair of CSF leaks with or without meningocele ${ }^{3}$. The size of a defect may be a limiting factor for endoscopic repair ${ }^{3}$, but we could draw no conclusions about this variable.

\section{Conclusion:}

Endoansal endoscopic approach is safe and effective in the management of basal meningocoele/ meningoencephalocoele. Complications of transcranial approach can be avoided by using this less invasive procedure.

\section{Reference:}

1. Muraszko KM. Encephalocoeles. In WilkinsRHRengachary SS (eds) Neurosurgery. McGraw-Hill.New York, 1996. 3573-79.

2. Lee TJ, Chang PH, Chuang CC. Endoscopic treatment of basal encephalpcoeles: a report of 8 cases.J Neurosurg. 2008; 108: $729-35$.

3. Arabi B, Leibrock LG. Nuerosurgical approaches to cerebrospinal fluid rhinorrhoea. Ear Nose Throat. 1992; 71: 300-305.
4. Garg P, Rathi V, Bhargava SK, Agarwal A. CSF Rhinorrhoea and Recurrent Meningitis Caused by Transethmoidal Meningoencephalocoeles. Indian Pediatrics. 2005; 42: 1033- 1036.

5. Formica F,Lannelli A, PalidettiG, Di Rocco C. Transsphenoidal meningoencephalocoele. Childs Nerv. Syst. 2002; 18: 295-98.

6. Woodworth BA, Schlosser RJ, Faust RA, Bolger WE. Evolution in the management of congenital skull base defects. Arch. Otolaryngol. Head Nech Surg. 2004; 130: 1283-88.

7. Kitano M, Taneda M. Subdural patch graft technique for water-tight closure of large dural defect in extended transsphenoidal surgery. Neurosurgery. 2004; 54:653-60.

8. Marton E, Billeci D, Schiesari E, Longatti P. Transnasal endoscopic repair of cerebrospinsal fluid fistula and encephalocoeles: Surgical indications and complications. Minim Invasive Neuosurg. 2005; 48:175-81.

9. Boseley ME, Tami TA. Endoscopic management of anterior skull-base encephalocoeles. Ann Otol Rhinol Laryngol. 2004; $113: 30-33$

10. Lanza DC, O'Berien DA, Kennedy DW. Endoscopic repair of cerebrospinal fluid fistula and encephalocoeles. Laryngoscope. 1996; 106: 1119-25.

11. Lee TJ, Huang CC, Chuang CC, Huang SF. Transnasal endoscopic repair of cerebrospinal fluid rhinorrhoea aqnd skull-base defect: ten-year experience. Laryngoscope. 2004; 114: 1475-81.

12. Marshall AH, Jones NS, Robertson IJA. Endoscopic management of basal encephalocoele. J Laryngol Otol. 2001; 115:545-47.

13. Wolansky LJ, Chiang PK, Zurlo J, Baredes S, Baker SR. Encephaloceleas a complication of intranasal sinus surgery: optimum evaluation with magnetic resonance imaging. J Laryngol Otol. 1998; 112:790-92.

14. Hamlin K, Kubba H. Endoscopic excision of nasal meningoencephalocoele in an infant.International journal of pediatric Otorhinolaryngology. 2007; 2:92-94.

15. D.J. David, Cephaloceles: classification, pathology, and management-review, J Craniofac Surg. 1993; 4:192-202

16. McCormack B, Cooper PR, Persky M, Rothstein S, Extracranial repair of cerebrospinal fluid fistulas: technique and results in 37 patients, Neurosurgery. 1990; 27:412-17.

17. McCormack B, Cooper PR, Persky M. External repair of cerebrospinal fluid fistulas: techniques and results in 37 patients. Neurosurgery $1990 ; 25: 412-417$.

18. Casler JD, Doolittle AM, Mair EA. Endoscopic surgery of the anterior skull base. Laryngoscope. 2005; 115:16-24.

19. Arita N, Mori S, Sano M, Hayakawa T, Nakao K, Kanai N, et al. Surgical treatment of tumors in the anterior skull baseusing the transbasal approach. Neurosurgery 1989;24:379-84.

20. Zweig JL, Carrau RL, Celin SE, Snyderman CH, Kassam A, Hegazy H. Endoscopic repair of acquired encephaloceles, meningoceles, and meningo-encephaloceles: predictor of success. Skull Base 2002; 12(3):133-39.

21. Mattox D.E., Kennedy D.W. Endoscopic management of cerebrospinal fluid leaks and cephaloceles, Laryngoscope 1990; 100: $857-862$. 
22. Stankiewicz J.A. Complications of endoscopic intranasal ethmoidectomy, Laryngoscope $1987 ; 97: 1270-73$.

23. Lanza DC, O'Brien DA, Kennedy DW. Endoscopic repair of cerebrospinal fluid fistulae and encephaloceles, Laryngoscope 1996; 106: 1119-25.

24. Marshall AH, Jones NS, Robertson IJ. Endoscopic management of basal encephaloceles, J. Laryngol. Otol. 2001; 115: 545 - 547.

25. Shetty P, Shroff MM, Sahani DV. Evaluation of high-resolution CT and MR cisternography in the diagnosis of cerebrospinal fluid fistula. Am J Neuroradiol 1998; 19:633-39.

26. Wigand ME. Transnasal ethmoidectomy under endoscopic control. Rhinology. 1981;19:7-15.

27. Weber R, Keerl R, Drat W, et al. Management of dural lesions occurring during endonasal sinus surgery. Arch Otolaryngol Head
Neck Surg 1996; 122:732-36.

28. Buchman CA, Civantos FJ, Casiano RR. Skull base cerebrospinal fluid leaks and encephaloceles. In: Advances in

Otolaryngology-Head and Neck Surgery. Vol 13. St. Louis, MO: Mosby Inc; 1999.

29. Burns J, Dodson E, Gross C. Transnasal endoscopic repair of cranionasal fistulae: a refined technique with long-term follow-up. Laryngoscope 1996;106:1080-83

30. Hegazy HM, Carrau RL, Snyderman CH, Kassam A, Zweig J, Transnasal-endoscopic repair of cerebrospinal fluid rhinorrhea: a meta-analysis. Laryngoscope 2000;110:1166-1172

31. Serbetci E, Sengor GA. Transnasal endoscopic approach for anterior skull base angiomatosis complicated by meningocele. Kulak Burun BogazlhtisDerg (Turkey). 2008;18(4): 242-45. 